\title{
Nodular Fasciitis Presenting in the Obturator Nerve and Gracilis Muscle
}

\author{
Aria Fallah, Joey Grochmal, Jian-Qiang Lu, Lisa M. DiFrancesco, Moosa Khalil, \\ Arthur W. Clark, Rajiv Midha
}

Can. J. Neurol. Sci. 2008; 35: 111-114

Nodular fasciitis is a reactive proliferation of fibroblasts/ myofibroblasts characterized by a rapidly growing non-tender subcutaneous mass and subsequently self-limited course. ${ }^{1-4}$ It is commonly found on the upper extremities, face, and shoulder, although it may occur in any superficial location. ${ }^{3-5}$ Its etiology is largely unknown, but associations have been made with local trauma, infection and inflammation. ${ }^{1,4,6}$ We report a case of an intraneural and intramuscular nodular fasciitis presenting in the obturator nerve and gracilis muscle, respectively. To our knowledge, this is the second reported case of this disease presenting in a nerve of the lower extremity, ${ }^{1}$ as well as the first reported case of it presenting within muscle and nerve simultaneously.

\section{Case Report}

A 34-year-old woman at three months post-partum presented as an outpatient complaining of a one-two month history of a rapidly growing lump in her left proximal medial thigh causing mild local discomfort. She had previous excision of dermatofibromas from the left ankle and right wrist in the past year. She denied any personal or family history of neurofibromatosis (NF). Apart from an uncomplicated vaginal delivery, there was no other history of local trauma, overuse, or any constitutional symptoms. On examination, there were no stigmata of neurofibromatosis. The neurological examination of the left lower extremity was normal in terms of muscle power, sensation, and deep tendon reflexes. An indiscrete, non-tender, non-mobile and relatively small lesion was palpated in the superior aspect in the left medial thigh. The lesion appeared to be deep to the gracilis muscle and just inferior to the adductor origin from the pelvic bone.

Ultrasound revealed a solid nodule with a cystic core in the inner aspect of the left thigh. Magnetic resonance imaging (MRI) visualized a well-defined oval mass lesion within the soft tissue plane between the left gracilis and adductor muscles, measuring $3.3 \times 3.0 \times 3.7 \mathrm{~cm}$. On T1-weighted imaging, the mass demonstrated homogenous hypointensity, while being of moderate-high intensity on the $\mathrm{T} 2$-weighted sequences. Following gadolinium administration, there was intense homogenous peripheral enhancement with a non-enhancing irregular central core (Figure 1). The mass appeared to have a well-defined capsule and did not appear to be associated with any definable neurovascular bundle. These findings were suggestive of a soft tissue lesion, whose differential diagnosis includes lipoma, fibroma, muscle tumours, schwannoma,

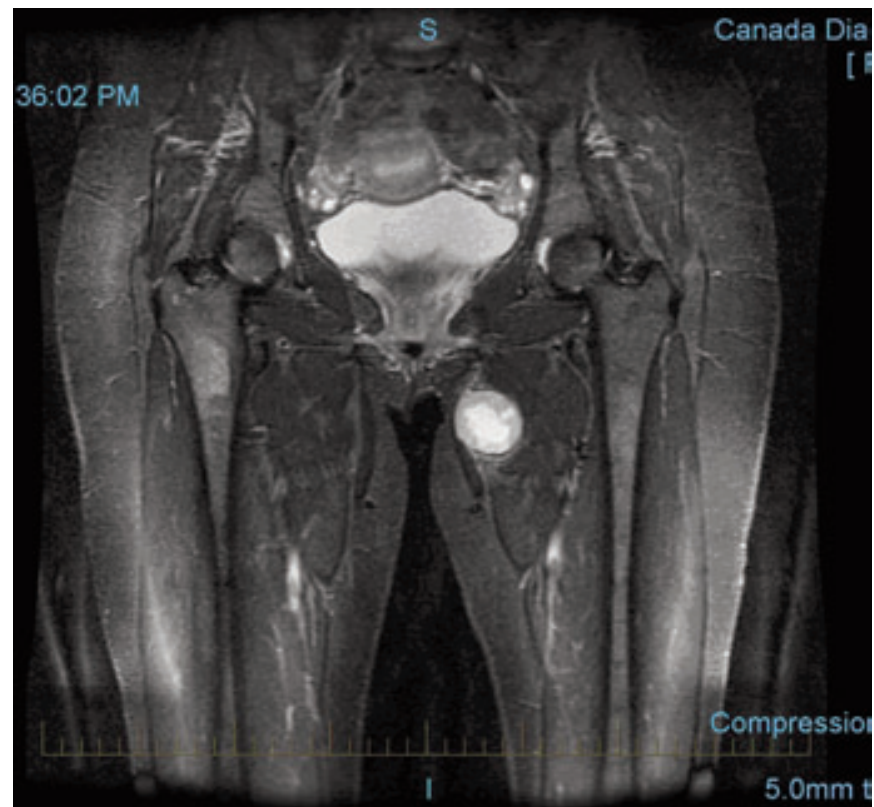

Figure 1. T2 Fat Saturation; Post-Gadolinium MRI. Coronal image demonstrating a $3.3 \times 3.0 \times 3.7 \mathrm{~cm}$ lesion, intimate with the gracilis and adductor musculature. Note the peripheral enhancement and central hyperintensity. An incidental lesion is noted in the metadyaphysis of the right femur.

neurofibroma, intraneural perineurinoma, sarcoma and inflammatory lesions. Even though a defined neurovascular bundle could not be seen in association with the lesion, the MR imaging features were most consistent with a nerve sheath tumour, such as a schwannoma or neurofibroma. Incidentally, a

From the Michael G. DeGroote School of Medicine (AF), McMaster University, Hamilton, Ontario; Division of Neurosurgery, Department of Clinical Neurosciences (JG, RM); Department of Pathology \& Lab Medicine (JQL, LMD, MK, AWC), University of Calgary, Calgary, Alberta, Canada

Received July 16, 2007. Final Revisions Submitted October 31, 2007. Reprint requests to: Rajiv Midha, Foothills Medical Centre, Room 1195, 1403-29th Street NW, Calgary, Alberta T2N 2T9, Canada. 


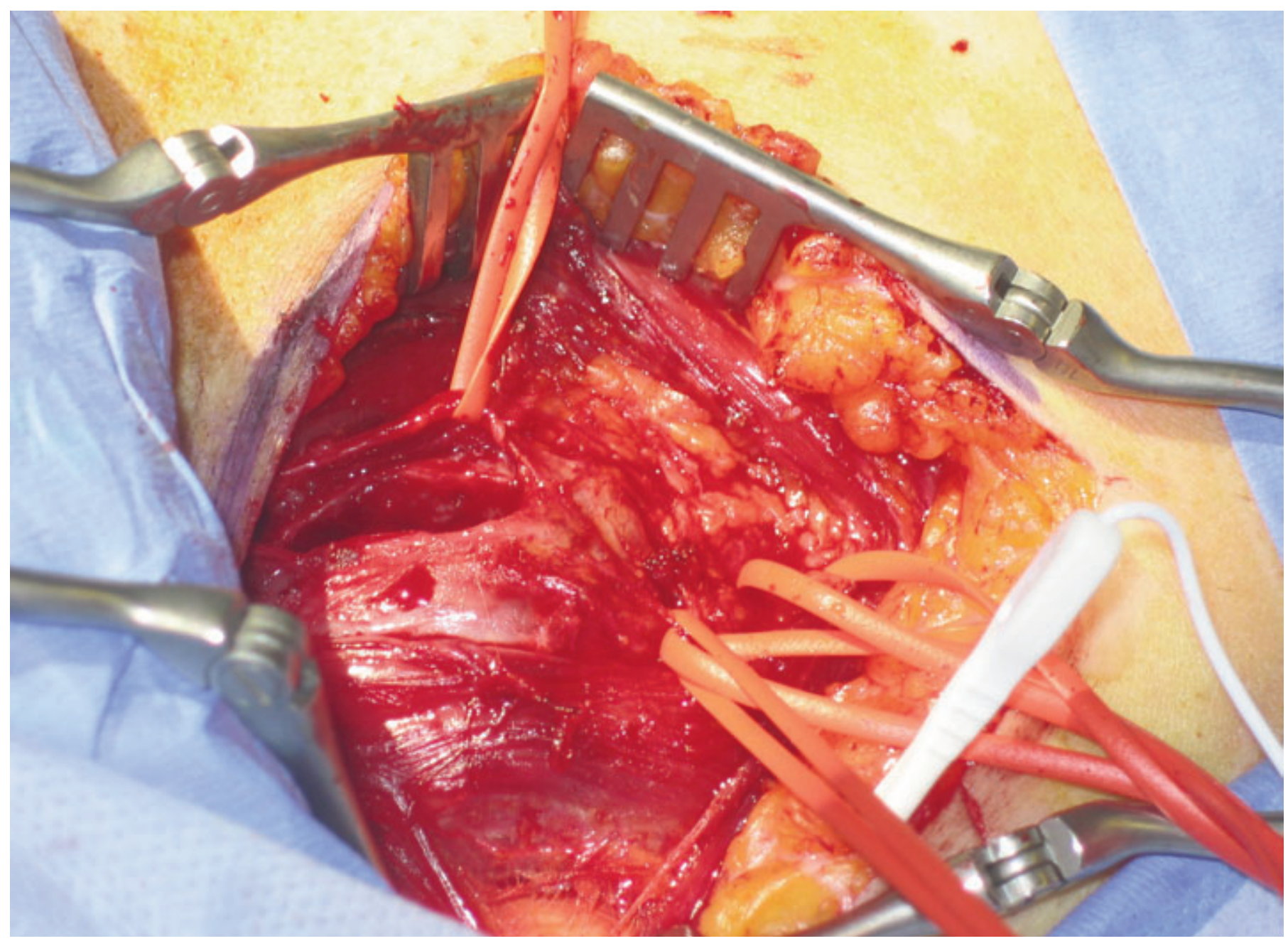

Figure 2. The obturator nerve was identified running both to and from the lesion, with obturator nerve fascicles (encircled by vasoloops) to gracilis muscle being intimately woven through the lesion periphery.

solitary intramedullary oval lesion $(4.5 \times 2.1 \times 2.1 \mathrm{~cm})$ was found within the metadiaphysis of the right femur (Figure 1), radiologically most consistent with fibrous dysplasia.

Given the rapid growth of the lesion and the concern for malignancy, the patient underwent surgical resection of the lesion. Following a vertical $5 \mathrm{~cm}$ incision in the medial left thigh, a $3 \mathrm{~cm}$ lesion was found to be deep to, but adherent to the overlying gracilis muscle tissue. The lesion was mobilized off of the muscle using blunt and sharp dissection. The obturator nerve was identified running both to and from the lesion, with obturator nerve fascicles (identified electrically as evoking contraction of the gracilis and adductor musculature) being intimately woven through the peripheral aspect of the lesion (Figure 2). At the inferior border of the lesion, a portion of the anterior branch of the obturator nerve trunk appeared to be slightly medial and somewhat posterior to the lesion itself, but the gracilis nerve branches were still quite intimately involved.
No intraoperative biopsy for frozen section was taken as the tumor appeared intraneural and was relatively well-defined. An incision was made through the lesion in a fascicle-free zone and the lesion was debulked internally. This was done in piece-meal fashion due to the rubber-like consistency of the tumour and because of the very intimate involvement of obturator nerve fascicles. A very extensive but sub-total resection was achieved. The tumour tissue was sent for histopathological examination.

Microscopic examination showed typical features of nodular fasciitis, with spindle cell proliferation set in a loosely textured mucoid matrix, and scattered chronic inflammatory cells (Figure 3). Immunohistochemical studies revealed that a great majority of cells exhibited strong immunoreactivity for Smooth Muscle Actin (Figure 3 inset), suggestive of their cellular origin of myofibroblasts. Overall absence of immunoreactivity for S100 excluded a significant involvement of Schwann cells. No neural component was identified microscopically. The patient remains 


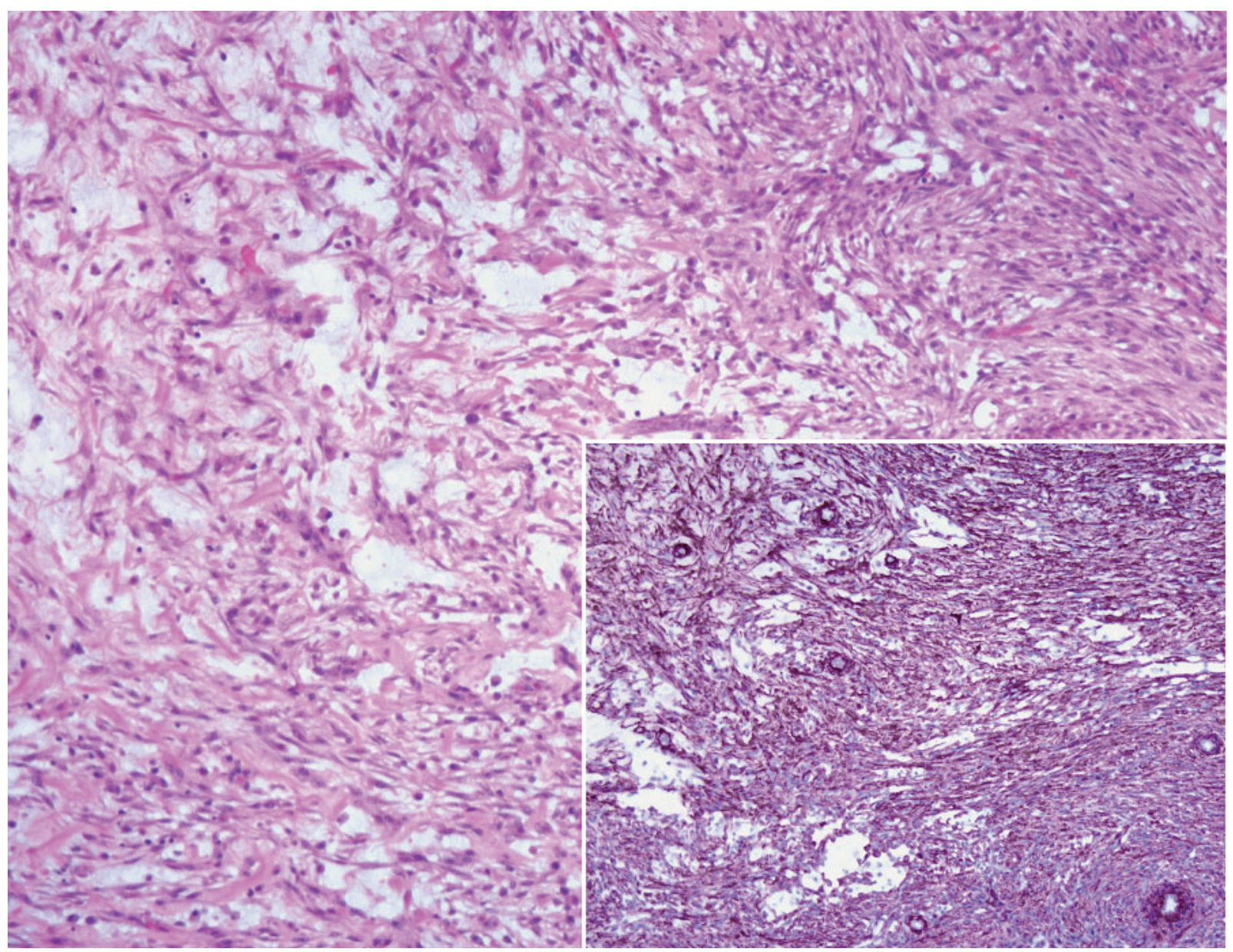

Figure 3. Histopathological section showing proliferation of spindle cells arranged in a loosely textured mucoid matrix, and infiltration of scattered chronic inflammatory cells (H\&E, original magnification $x$ 100); the inset demonstrating diffuse and strong immunoreactivity for Smooth Muscle Actin (original magnification x 100) confirmed that lesional cells were composed of myofibroblasts.

Table: Previously reported intraneural cases of nodular fasciitis

\begin{tabular}{|c|c|c|c|c|c|}
\hline Author, Year & $\begin{array}{l}\text { Age (Years), } \\
\text { Gender }\end{array}$ & $\begin{array}{l}\text { Clinical } \\
\text { Manifestation }\end{array}$ & Location & Radiology & $\begin{array}{l}\text { Surgical } \\
\text { Procedure }\end{array}$ \\
\hline $\begin{array}{l}\text { Mahon et al., } \\
2004^{4}\end{array}$ & 32, Male & $\begin{array}{l}\text { inability to } \\
\text { adduct right fifth } \\
\text { digit, decreasing } \\
\text { sensation in } \\
\text { ulnar aspect of } \\
\text { right hand }\end{array}$ & Ulnar nerve & $\begin{array}{l}\text { T1 -intermediate } \\
\text { intensity } \\
\text { T2 - increased } \\
\text { signal } \\
\text { Intensity }\end{array}$ & $\begin{array}{l}\text { Subtotal } \\
\text { resection }\end{array}$ \\
\hline $\begin{array}{l}\text { Ikeda et al., } \\
2005^{2}\end{array}$ & 42, Female & $\begin{array}{l}\text { Progressive } \\
\text { induration in the } \\
\text { right palm }\end{array}$ & Ulnar nerve & $\begin{array}{l}\mathrm{T} 1 \text { - low } \\
\text { intensity } \\
\mathrm{T} 2 \text { - high- } \\
\text { intensity }\end{array}$ & $\begin{array}{l}\text { Complete } \\
\text { resection of } \\
\text { lesion with } \\
\text { nerve, nerve } \\
\text { grafting }\end{array}$ \\
\hline $\begin{array}{l}\text { Parrett et al., } \\
2007^{1}\end{array}$ & 37, Female & Right thigh mass & Sciatic Nerve & $\begin{array}{l}\text { T1 - } \\
\text { hypointense } \\
\text { T2- } \\
\text { hyperintense }\end{array}$ & $\begin{array}{l}\text { Subtotal } \\
\text { resection }\end{array}$ \\
\hline
\end{tabular}

clinically well and there has been no evidence of recurrence at four months follow-up.

\section{DISCUSSION}

Konwaler, Keasbey and Kaplan were to first to coin the term 'pseudosarcomatous fibromatosis' or 'fasciitis' describing a benign lesion that was frequently incorrectly treated as a sarcoma due to its rapid growth and atypical histology., ${ }^{4,5}$ Over the next few decades, 'infiltrative fasciitis', 'nodular fibrositis' and 'subcutaneous fibromatosis' as well as 'nodular fasciitis' have been used to describe a similar disease entity. ${ }^{3,8}$ The three main forms of nodular fasciitis are subcutaneous, intramuscular and fascial. ${ }^{1,3,9}$ Although the occurrence of an intramuscular nodular fasciitis is not unknown, there have only been three cases of intraneural nodular fasciitis reported in the current literature. ${ }^{1,2,4,10}$ Two have presented within the ulnar nerve, with the other involving the sciatic nerve. ${ }^{1,2,4}$ In contrast, this is the first reported case of nodular fasciitis presenting simultaneously within a nerve and muscle. 
Due to its infrequent occurrence, most clinicians do not consider nodular fasciitis in the differential diagnosis of peripheral nerve tumours, commonly mistaking it for a schwannoma, neurofibroma or perineurioma. ${ }^{11,12}$ Considering the possibility of intramuscular or other soft tissue lesions, the differential diagnosis also includes lipoma, fibroma, and sarcoma. On MRI, it typically presents slightly hyperintense to skeletal muscle on T1-weighted images and hyperintense on T2weighted images with fat saturation. ${ }^{3}$ The lesions are frequently round to oval and are commonly under $4.5 \mathrm{~cm} .{ }^{13}$ More recently, there is some support for the use of positron emission tomography (PET) with ${ }^{18} \mathrm{~F}$-fluorodeoxyglucose contrast in discriminating between benign and malignant lesions. ${ }^{9}$ The limited uptake of the contrast by normal tissue makes interpretation easier. ${ }^{9}$ However, due to its high costs and the lack of PET scanners at many institutions, it is not always feasible. ${ }^{9}$

Histopathological features of nodular fasciitis include cellular myofibroblastic proliferation arranged in short interweaving fascicles, with myxoid stroma, scattered inflammatory cells, and frequent mitoses..$^{3,5,6,9}$ These findings in the context of a rapidly growing mass can lead to a misdiagnosis of a sarcoma. ${ }^{3,5,6,9}$ Consequently, the misdiagnosis of this tumour on frozen section as a more malignant lesion can result in excessively aggressive surgical resection and possible nerve and muscle dysfunction. ${ }^{4}$ Expert opinion advocates function-sparing excision as optimal treatment. ${ }^{1,8}$ Since the course of this lesion is benign and selflimited, it is also reasonable to simply monitor its course in asymptomatic cases through serial imaging. ${ }^{1,2,8}$ However, the concern for malignancy commonly results in diagnostic surgery. In those cases, excisional biopsy is recommended and examination of the histological sections by an experienced pathologist is required to make the diagnosis. ${ }^{1,4,5}$ Given the benign nature and less than two percent recurrence rate of nodular fasciitis, it may be reasonable to stop regular follow-up post total resection. ${ }^{2}$

Peripheral neurogenic tumours include neurofibromas, schwannomas, intraneural perineurinomas and malignant nerve sheath tumours. Neurofibromas are benign nerve sheath tumours that most frequently occur in the second decade of life and equally amongst genders. ${ }^{14}$ The localized variety, the most common form, is not linked with NF-1 and can manifest as a solitary lesion involving a deep nerve. ${ }^{14}$ On MR imaging, these tumours demonstrate low to intermediate signal intensity on T1weighted images and high signal intensity on T2-weighted images, respectively. ${ }^{14}$ Contrast enhancement is seen in the majority of cases. ${ }^{14}$ Schwannomas are benign nerve sheath tumours commonly presenting in adulthood with no gender bias. ${ }^{14}$ They typically appear as solitary, non-painful, fusiformshaped lesions occurring in the head and neck region as well as major nerve trunks. ${ }^{14}$ They are typically difficult to distinguish from neurofibromas on neuroimaging as they have similar characteristic features. ${ }^{14}$ One helpful distinguishing feature is its relation to the parent nerve: schwannomas appear more eccentrically while neurofibromas tend to occur centrally. ${ }^{14}$ Intraneural perineurinoma is a benign neoplastic proliferation of perineurial cells that is associated with trauma but not currently shown to be related to neurofibromatosis. ${ }^{11}$ It typically occurs in early adulthood as a slow-growing and painless mononeuropathy. ${ }^{11}$ Since it is a rare and relatively recently studied lesion, the lack of evidence prevents making further definitive statements about this disease entity. Malignant peripheral nerve sheath tumour arises from nerve or neurofibroma, is typically discovered in adulthood and is associated with NF-1 in up to $50 \%$ of patients. ${ }^{14}$ They commonly involve major trunks. ${ }^{14}$ Pain and neurological deficits are more commonly associated than in benign tumours. ${ }^{14}$ Although, neuroimaging provides limited value in differentiating this malignant type, large tumours $(>5 \mathrm{~cm})$, heterogeneity, poorly defined borders and invasion all favour this diagnosis. ${ }^{14}$

\section{CONCLusion}

Nodular fasciitis involving the nerve is a relatively recently reported occurrence. This is the first reported simultaneous occurrence in muscle and nerve. It is prudent to consider this diagnosis in the differential whenever an atypical case of sarcoma, schwannoma or neurofibroma is encountered.

\section{REFERENCES}

1. Parrett BM, Orgill DP, Marsee DK, Freedman AS, Raut CP. Novel presentation of intraneural nodular fasciitis of the sciatic nerve. $\mathrm{J}$ Peripher Nerv Syst. 2007;12(1):61-3.

2. Ikeda K, Norio H, Funaki K, Tomita K, Sudo Y. Nodular fasciitis of the ulnar nerve at the palm. Scand J Plast Reconstr Surg Hand Surg. 2005;39(4):249-51.

3. Leung LYJ, Shu SJ, Chan ACL, Chan MK, Chan CHS. Nodular fasciitis: MRI appearance and literature review. Skeletal Radiol. 2002;31(1):9-13.

4. Mahon JH, Folpe AW, Ferlic RJ. Intraneural nodular fasciitis: case report and literature review. J Hand Surg. 2004;29(1):148-53.

5. Culberson JD, Enterline HT. Pseudosarcomatous fasciitis: a distinctive clinical-pathologic entity: report of five cases. Ann Surg. 1960;151:235-40.

6. Kleinstiver BJ, Rodriguez HA. Nodular fasciitis. A study of fortyfive cases and review of the literature. J Bone Joint Surg Am. 1968; 50(6):1204-12.

7. Shimizu S, Hashimoto H, Enjoji M. Nodular fasciitis: an analysis of 250 patients. Pathology. 1984;16(2):161-6.

8. Bernstein KE, Lattes R. Nodular (pseudosarcomatous) fasciitis, a nonrecurrent lesion: clinicopathologic study of 134 cases. Cancer. 1982;49(8):1668-78.

9. Kessels LW, Simsek S, van Hattum AH, Stam F, Comans EFI. Nodular fasciitis: an unexpected finding on computed tomography and positron emission tomography. Eur J Intern Med. 2004;15(3)183-5.

10. Hansen T, Katenkamp K, Katenkamp D. Intramuscular nodular fasciitis - a clinicopathological study with emphasis on myogenic giant cells. Pathologe. 2006;27(3):198-203.

11. Boyanton BL, Jones JK, Shenaq SM, John Hicks M, Chattacharjee MB. Intraneural perineurioma a systematic review with illustrative cases. Arch Pathol Lab Med. 2007;131(9):1382-92.

12. Zuber TJ, Finley JL. Nodular fasciitis. South Med J. 1994; 87(8):842-4.

13. Meyer CA, Kransdorf MJ, Jelinek JS, Moser RP. MR and CT appearance of nodular fasciitis. J Comput Assist Tomogr. 1991;15(2):276-9.

14. Pilavaki M, Chourmouzi D, Kiziridou A, Skordalaki A, Zarampoukas T, Drevelengas A. Imaging of peripheral nerve sheath tumors with pathologic correlation pictorial review. Eur J Radiol. 2004;52(3):229-39. 